The Egyptian International Journal of Engineering Sciences \& Technology, Vol 3, No 1 (1999)

\title{
A New Approach for Monitoring Deformation of Buildings
}

Samir Eisa, AbdelHaleem Behairy

\begin{abstract}
The two main forms of buildings' deformations are tilt and settlement. The main sources of these deformations are wind, vibration, moving traffic, and foundations' movement caused by either total or differential settlement. The shape and deformation of an object vertical plane which represent the building facade can determined knowing the space coordinates of a group of points which are well distributed on the required building facade. The space coordinates of these pomts can be determined using surveying, photogranmietric, or combined technique. The required measurements are the horizontal and the vertical directions to each of these objects points from a two theodolite stations setting at a suitable location relative to the object vertical plane. This article gives the best location of the two theodolite stations to obtain thie required coordinates with minimum errors
\end{abstract}

